\title{
Simulation on stress of large diameter CADI grinding ball based on ANSYS
}

\author{
Xue-bo Zhao, Jian-shuai Yan, *Jin-hai Liu, Bin-guo Fu, Wei-ting Yang, and Guo-lu Li
}

School of Materials Science and Engineering, Hebei University of Technology, Tianjin 300130, China

\begin{abstract}
The falling ball tests were carried out on the $\Phi 125 \mathrm{~mm}$ diameter Carbidic Austempered Ductile Iron (CADI) grinding balls with Mn content of 2.0wt.\%, 2.3wt.\%, 2.6wt.\% and 3.0wt.\%, respectively, and the kind of grinding ball with the most serious spalling was selected for stress simulation. The stress distribution between four grinding balls in the elbow of the falling ball test device when they collided with each other was simulated based on ANSYS. Results of the falling ball tests show that the spalling and mass loss of a CADI grinding ball increases with the increase of $\mathrm{Mn}$ content, and the CADI grinding ball with 3.0wt.\% Mn shows the most obvious spalling and mass loss. The simulation results of stress distribution of a CADI grinding ball show that the maximum impact stress does not appear in the center of the contact area, but in the annular area (inner diameter of $\sim 20 \mathrm{~mm}$ and outer diameter of $\sim 50 \mathrm{~mm}$ ) in the section with a depth of 5-15 mm below the grinding ball surface. The actual spalling of the ball is consistent with the simulation results, and the oxide-based impurities in CADI grinding ball accelerate the spalling of the grinding ball in service.
\end{abstract}

Key words: CADI; stress; grinding ball; ANSYS

CLC numbers: TG143.5 Document code: A Article ID: 1672-6421(2020)03-227-08

$\mathrm{C}$ ADI (Carbidic Austempered Ductile Iron) is a new kind of wear-resistant material developed on the basis of ADI ${ }^{[1]}$ (Austempered Ductile Iron). There are many studies concerning CADI, such as on chemical composition ${ }^{[2-5]}$, microstructure ${ }^{[6,7]}$, properties ${ }^{[8-11]}$ and heat treatment ${ }^{[12-15]}$. The matrix structure of ADI is composed of the acicular ferrite with high hardness, and the strong and ductile retained austenite. Increasing the carbides can greatly improve the wear-resistance of CADI, so that the application of CADI in the mining industry with great wear and tear consumption is increasing day by day. Wear-resistant metal materials such as grinding balls, liners, bucket teeth and drill bits are consumed at a rate of more than 4.05 million tons every year in China, among which grinding balls are the largest part, accounting for $43 \%$ of the total of wear-resistant materials ${ }^{[16]}$. Compared with steel balls (such as medium carbon steel balls, high carbon steel balls) and other iron balls (such as ordinary white iron balls, high chromium iron balls), the grinding ball made of CADI has the advantages of light weight, low cost, energy saving, and low rate of consumption, so the

\section{*Jin-hai Liu}

Male, born in 1957, Professor, Ph.D. His research interests mainly focus on cast alloys and their forming technologies.

E-mail: jhliugongda@gmail.com

Received: 2019-11-11; Accepted: 2020-03-06
CADI grinding ball ${ }^{[17,18]}$ has a greater market prospect and research value.

The application of a large-scale ball mill is the development trend of the modern mineral processing industry. When the size of the mill increases, the size of the ore added and the diameter of the grinding ball also increases. At present, there are many studies on large diameter steel balls, but few on large diameter CADI grinding balls. When the grinding ball is in service in the mill, it constantly collides with the ore, other grinding balls and lining plate. Under the action of the impact force, the ball is constantly deformed, worn and even peeled off, which causes the ball to lose its roundness and fail ${ }^{[19]}$. With the increase of the size of mill and grinding ball, the service conditions of grinding balls in a mill are even worsened, and spalling becomes more and more serious. The accumulation of impact stress and residual stress produced in the service process of a grinding ball is the main cause of surface peeling. Therefore, research on the internal stress field of grinding balls in service is increasingly urgent, but little attention was paid.

There are many methods to study the internal stress of workpieces, and numerical simulation undoubtedly is a reliable, non-destructive, intuitive and fast method. ANSYS is a powerful software, which is widely used in temperature field ${ }^{[20-22]}$ and stress ${ }^{[23,24]}$ simulations of castings. 
The stress distribution of a $\Phi 100 \mathrm{~mm}$ CADI grinding ball, when two balls collide, was simulated ${ }^{[25]}$, but there still exists some difference when multi-balls collide in the falling ball test. Therefore, this study focuses on the simulation and analysis of stress of the $\Phi 125 \mathrm{~mm}$ CADI grinding balls when multi-balls collide during falling based on ANSYS, aiming to effectively analyze the behavior and cause of CADI grinding ball failure, so as to play a guiding role in improving the wear resistance of the grinding ball in production.

\section{Experimental procedure}

\subsection{Experimental materials}

Pig iron, scrap steel, ferromanganese, ferrosilicon, low carbon ferrochromium and copper sheet were used as the charge materials and melted in a medium frequency induction furnace with a capacity of $0.5 \mathrm{t}$. The melt at $1,550{ }^{\circ} \mathrm{C}$ was transferred to the casting ladle, and then the spheroidizing treatments were carried out by the cored-wire injection process. The treated molten iron was poured into the metal mold with a sand liner in cavity. Four alloys of ductile iron with different contents of manganese were obtained with the chemical compositions listed in Table 1. A schematic diagram of grinding balls with a diameter of $125 \mathrm{~mm}$ is shown in Fig. 1.

Table 1: Chemical compositions of CADI grinding balls (wt.\%)

$\begin{array}{ccccccc}\text { C } & \text { Si } & \text { Mn } & \text { Cr } & \mathrm{Cu} & \text { P } & \text { S } \\ & & 2.0 & & & & \\ & & 2.3 & & & & \\ 3.3-3.8 & 2.4-2.9 & & 0.4-0.7 & 0.5-0.7 & <0.06 & <0.03 \\ & & & & & & \\ & & 3.0 & & & & \\ & & & & & & \end{array}$

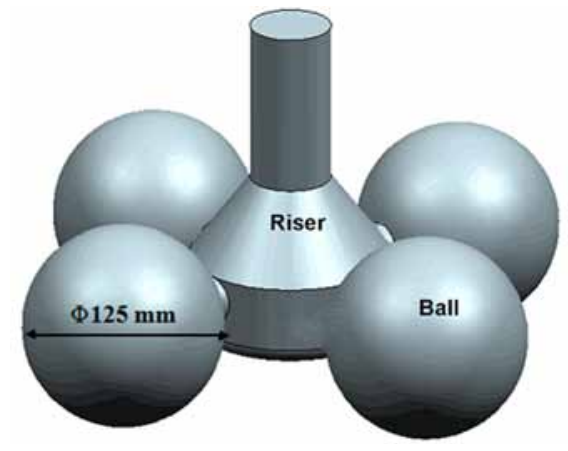

Fig. 1: Schematic diagram of grinding ball

\subsection{Heat treatment process}

Heat treatment of as-cast grinding ball was employed for CADI, consisting of austenitization and austempering process. The grinding ball was heated to $920{ }^{\circ} \mathrm{C}$ for $3 \mathrm{~h}$, then, quenched in molten salt bath $\left(50 \% \mathrm{KNO}_{3}+50 \% \mathrm{NaNO}_{2}\right)$ at $260{ }^{\circ} \mathrm{C}$ for $20 \mathrm{~min}$. Subsequently, isothermal transformation was held at $260{ }^{\circ} \mathrm{C}$ for $2.5 \mathrm{~h}$ in an electric resistance furnace.

\subsection{Falling ball test}

The equipment used for the falling ball test is the lifting type of impact fatigue testing device by cyclic drop of the ball. The structure of the falling ball testing device is shown in Fig. 2(a), and the schematic diagram of the device is shown in Fig. 2(b). The falling distance of the CADI grinding ball $(H)$ is about $10 \mathrm{~m}$. By means of chain drive, the grinding ball is raised to the top falling ball platform. Under the restriction of the guide device, the grinding ball enters the guide rail, falls freely along the guide rail, impacts the grinding ball on the top in the lower bend pipe, and forces out the ball at the other end of the bend pipe. The extruded ball rolls to the chain waiting for a new round of falling test. Every time a ball falls, it is counted once. (a)

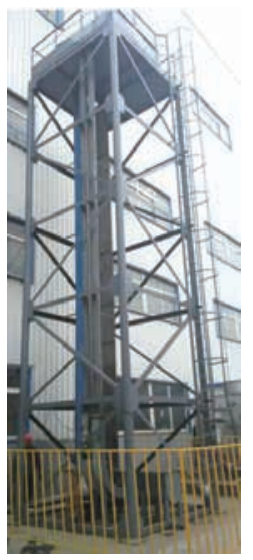

(b)

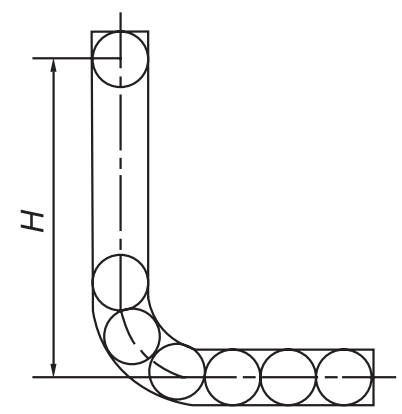

Fig. 2: Falling ball testing device (a) and its schematic diagram (b)

Nineteen CADI grinding balls with a diameter of $125 \mathrm{~mm}$ used in the falling ball test were randomly selected from the batch, and the surface of all balls was smooth and burr-free. Among the nineteen CADI grinding balls, twelve balls were placed in the bending pipe of the falling ball test device, four balls were used for external circulation, and the other three balls were used as the replacement balls with clear mark to avoid confusion.

Throughout the falling ball test, the device should run smoothly, and there are always sixteen balls circulating in the device. If the average diameter of the spalling layer on the surface of the CADI grinding ball is greater than $20 \mathrm{~mm}$ and the thickness is more than $5 \mathrm{~mm}$, or the CADI grinding ball breaks along the middle part, the ball is considered to have failed. Then, remove the failed ball and place one replacement ball until a third failed ball appears. Respectively record the number of ball drops in the three tests until the ball is out of service. The impact fatigue test life of the falling-ball is given in the following Eq. (1):

$$
N_{\mathrm{f}}=\frac{2 B_{\mathrm{t}}}{B_{\mathrm{s}}} \times \frac{N_{1}+N_{2}+N_{3}}{3}
$$

where $N_{\mathrm{f}}$ is the impact fatigue test life of CADI grinding ball (times), $B_{\mathrm{t}}$ is the number of grinding balls in the bending pipe of the falling ball test device, $B_{\mathrm{s}}$ is the total number of grinding 
balls run by the drop test system, $N_{1}$ is the number of times the ball dropped when the first CADI grinding ball fails, $N_{2}$ is the number of times of the ball dropped when the second CADI grinding ball fails, $N_{3}$ is the number of times of the ball dropped when the third CADI grinding ball fails.

\subsection{Simulation of stress of CADI grinding ball in a single drop}

ANSYS/LS-DYNA, which mainly displays nonlinear dynamic analysis and has static analysis function, is the most commonly used finite element analysis software for structural problems, such as large deformation, dynamics and multiple nonlinearity. Based on the finite element analysis software ANSYS/LSDYNA, stress field of a CADI grinding ball during the falling ball test with a single drop was simulated.

The falling ball was simplified to a symmetric model for simulation analysis, displayed by the SOLID162 element type of two-dimensional structured solid element. The specific material parameters used for the ball are shown in Table 2 .

Table 2: Material parameters of CADI grinding ball

\begin{tabular}{ccccc}
$\begin{array}{c}\text { Elasticity } \\
\text { modulus }(\mathrm{Pa})\end{array}$ & $\begin{array}{c}\text { Poisson } \\
\text { ratio }\end{array}$ & $\begin{array}{c}\text { Yield } \\
\text { strength }(\mathbf{P a})\end{array}$ & $\begin{array}{c}\text { Density } \\
\left(\mathbf{k g} \cdot \mathbf{m}^{-3}\right)\end{array}$ & $\begin{array}{c}\text { Tengent } \\
\text { modulus }(\mathrm{Pa})\end{array}$ \\
\hline $1.7 \times 10^{11}$ & 0.27 & $4 \times 10^{8}$ & 7,200 & $1.7 \times 10^{9}$ \\
\hline
\end{tabular}

The calculation of a three-dimensional model required higher computer performance and longer solving time, and the material of the grinding ball was considered as the isotropic medium, so a two-dimensional axisymmetric model was selected in this experiment. The \#1-\#4 models of grinding ball are shown in Fig. 3 (the stress generated by the impact of the falling ball has the most obvious effect on the topmost

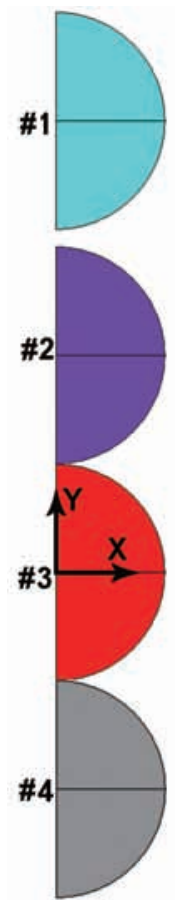

Fig. 3: Symmetry model of CADI grinding ball ball in the bend, so the \#1 drop ball and the top \#2-\#4 balls in the elbow are selected). After the axisymmetric model of the $\Phi 125 \mathrm{~mm}$ CADI grinding ball is established, the elements of the model are divided using a mapping method. The mesh size is $0.25 \mathrm{~mm}$, and the unit division result is shown in Fig. 4 .
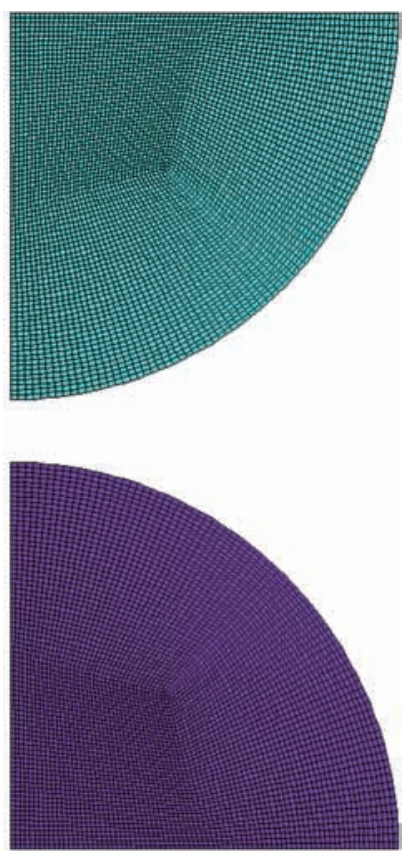

Fig. 4: Mesh division of CADI grinding ball model

When simulating the ball falling, only gravity acceleration is considered, while the air resistance is ignored. In order to reduce the calculation time, in the free-falling process, the initial drop speed of the top \#1 ball is set to $10 \mathrm{~m} \cdot \mathrm{s}^{-1}$, not $0 \mathrm{~m} \cdot \mathrm{s}^{-1}$. The simulation analysis was started when the distance between the $\# 1$ ball and the \#2 ball was $10 \mathrm{~mm}$. The grinding ball moves freely in the impact fatigue testing device, so the acceleration of gravity of $9.8 \mathrm{~m} \cdot \mathrm{s}^{-2}$ is applied to the model; the $\# 4$ grinding ball is set as a rigid body to be constrained and fixed, and the solution time is set to $0.004 \mathrm{~s}$. After the ANSYS calculation is completed, the general post-processing (Post 1) and time postprocessing (Post 26) were used to verify the simulation results.

\section{Results and discussion}

\subsection{Microstructure}

Figure 5 shows the microstructures of $2.0 \mathrm{wt} . \% \mathrm{Mn}, 2.3 \mathrm{wt} . \%$ Mn, 2.6wt.\% Mn, and 3.0wt.\% Mn CADI samples. It can be seen that the microstructures of $2.0 \mathrm{wt} . \% \mathrm{Mn}$ and $2.3 \mathrm{wt} . \%$ Mn CADI samples are relatively uniform, the microstructure of ausferrite is relatively dense, and the amount of carbide is less. When the Mn content increases to 2.6wt.\% and 3.0wt.\%, ausferrite decreases and carbides increase, especially in the microstructure containing 3.0wt.\% Mn.

\subsection{Impact fatigue property of CADI grinding ball}

During the operation of the falling ball testing device, the grinding ball is continuously lifted, the free-falling body 

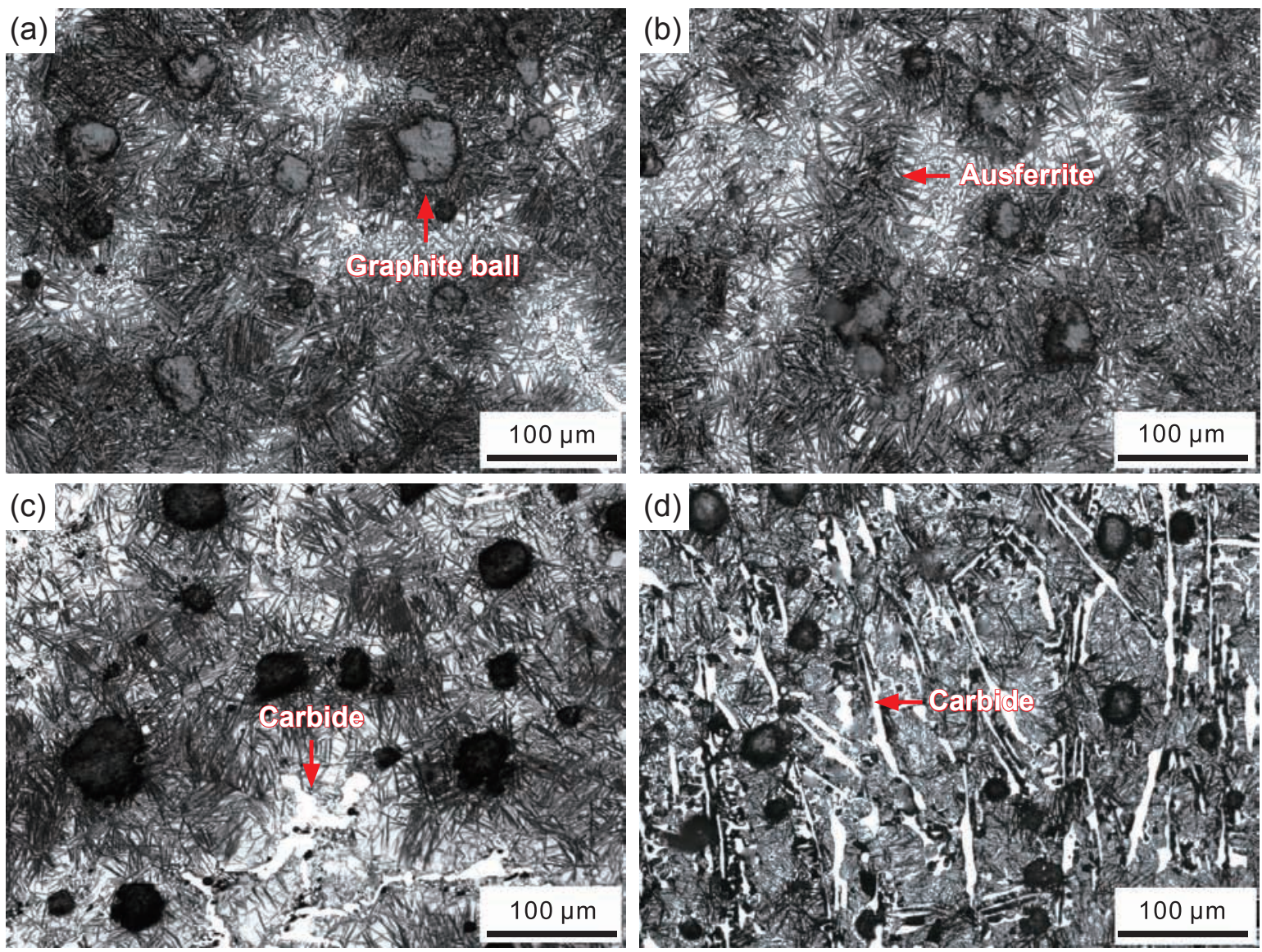

Fig. 5: OM microstructure of CADI samples with different contents of Mn: (a) 2.0wt.\%; (b) 2.3wt.\%; (c) 2.6wt.\%; (d) $3.0 \mathrm{wt} . \%$

moves, and collides with the bottom grinding ball. This test is the most effective method to evaluate the anti-spalling and anti-breaking ability of the grinding ball. The morphologies of the grinding balls with different Mn contents after 20,000 times of the impact fatigue test are shown in Fig. 6.

From Fig. 6, it can be seen that the surface of $2.0 \mathrm{wt} . \% \mathrm{Mn}$ CADI grinding ball is relatively smooth, round and almost non-spalling, the other grinding balls have different degrees of spalling. The 3.0wt.\% Mn grinding ball has the largest area of spalling. Table 3 lists the mass loss of CADI grinding balls after the falling ball test. Percentage of peeling of the grinding ball with $3.0 \mathrm{wt} . \% \mathrm{Mn}$ is about $11 \%$, which is at least five times as much as the other three. Combining Fig. 6 with Table 3 , it can be concluded that spalling is the main cause of mass loss. The internal stress produced by the impact of the grinding ball is one of the reasons for the peeling off of the grinding ball ${ }^{[19]}$. So, it is very important to simulate the stress and its distribution in the process of falling ball.

\subsection{Simulation of stress distribution of CADI grinding ball by single drop}

Based on Mises yield criterion ${ }^{[26]}$, when the potential energy of shape changes per unit volume in materials reaches a critical value under certain deformation conditions, the material will yield, so the greatest risk area of the model can be rapidly confirmed through analysis of the distribution of von-Mises stress within the physical model. Residual stress accumulates inside the CADI ball in service resulting from plastic deformation after
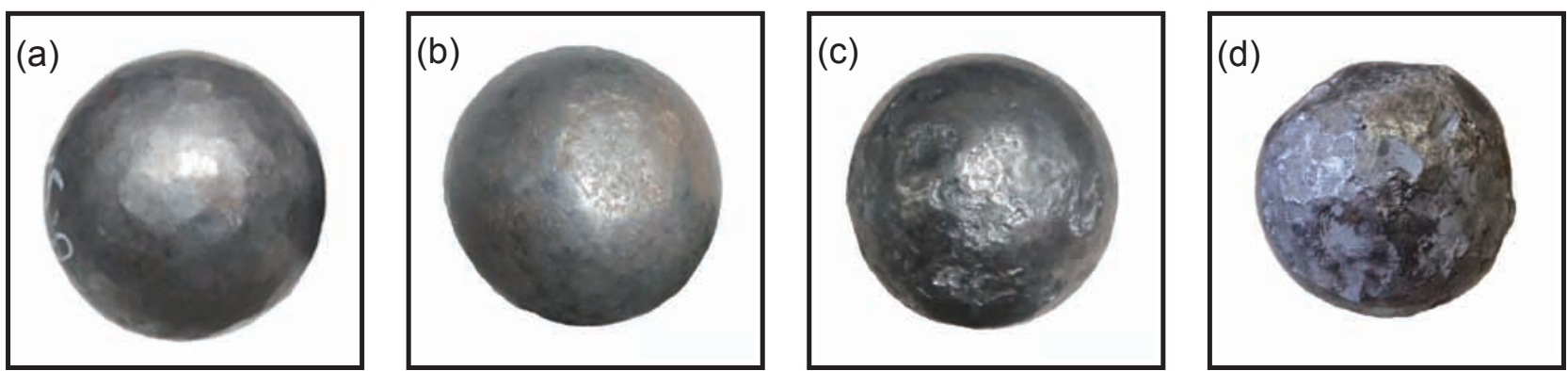

Fig. 6: Peeling shape of CADI grinding balls after falling 20,000 times: (a) $2.0 \mathrm{wt} . \% \mathrm{Mn}$; (b) $2.3 \mathrm{wt} . \% \mathrm{Mn}$; (c) $2.6 \mathrm{wt} . \% \mathrm{Mn}$; (d) $3.0 \mathrm{wt} . \% \mathrm{Mn}$ 
Table 3: Mass loss of CADI grinding balls after falling test

\begin{tabular}{cccccc}
$\begin{array}{c}\text { Mn content } \\
\text { (wt.\%) }\end{array}$ & $\begin{array}{c}\text { Number of ball } \\
\text { drops }\end{array}$ & $\begin{array}{c}\text { Original average } \\
\text { weight }(\mathbf{k g})\end{array}$ & $\begin{array}{c}\text { Average weight after } \\
\text { dropping (kg) }\end{array}$ & $\begin{array}{c}\text { Average peeling } \\
\text { (kg) }\end{array}$ & $\begin{array}{c}\text { Percentage of } \\
\text { peeling (wt.\%) }\end{array}$ \\
\hline 2.0 & 20,000 & 7.45 & 7.405 & 0.045 & 0.604 \\
2.3 & 20,005 & 7.44 & 7.361 & 0.079 & 1.058 \\
2.6 & 20,023 & 7.56 & 7.399 & 0.156 & 2.065 \\
3.0 & 20,000 & 7.42 & 6.610 & 0.810 & 10.900
\end{tabular}

impact, therefore residual stress of the ball may be simulated and analyzed on the basis of Mises yield criterion.

The actual working conditions of CADI grinding balls are closely simulated by the falling ball test. In the test, the interaction between the balls was similar during every drop, therefore simulation of residual stress of the CADI ball during the single drop was obtained as shown in Fig. 7. The axisymmetric model of the ball in Fig. 3 is applied to a complete two-dimensional model. (a)

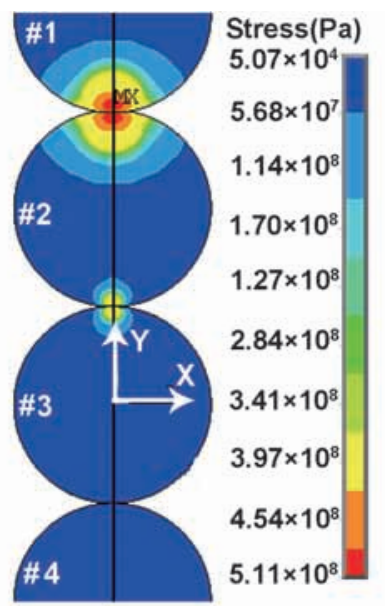

(b)

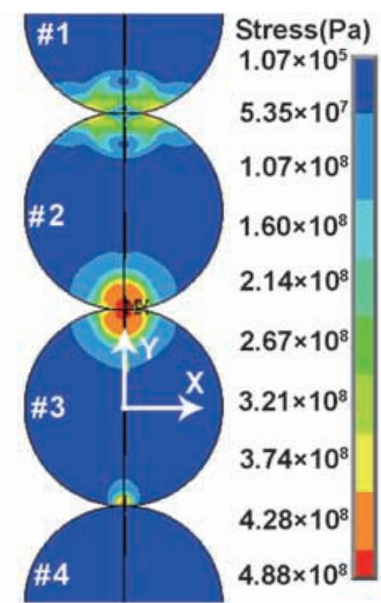

(c)

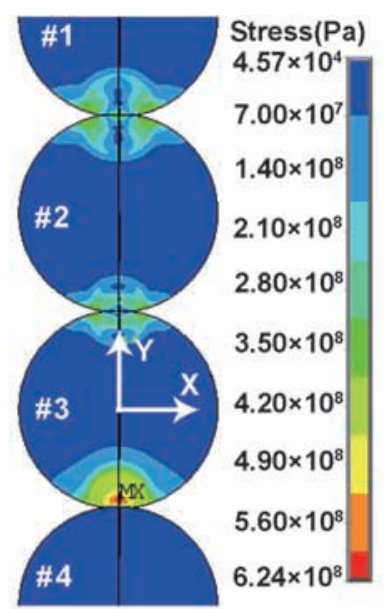

(d)

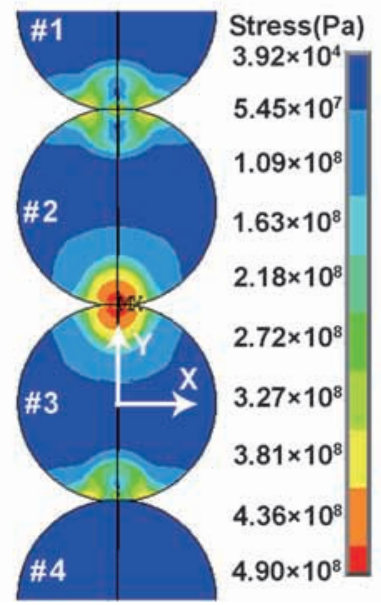

(e)

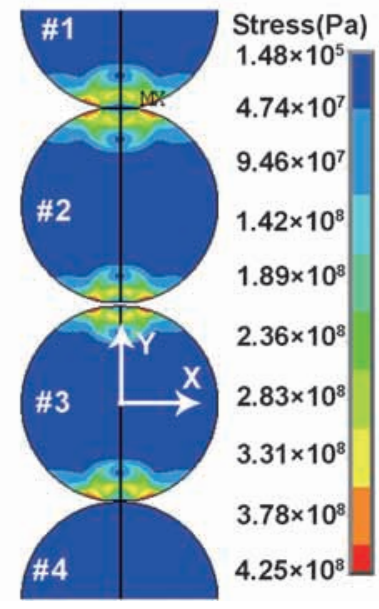

Fig. 7: Distribution of equivalent stress of CADI grinding balls at different moments in the single drop: (a) $0.87 \mathrm{~ms}$; (b) $1.0 \mathrm{~ms}$; (c) $1.28 \mathrm{~ms}$; (d) $1.37 \mathrm{~ms}$; (e) $3.5 \mathrm{~ms}$

As can be seen in Fig. 7(a), the stress in the contact center of the two balls is the greatest (more than $510 \mathrm{MPa}$ ) when the $\# 1$ ball is in contact with the \#2 ball at $0.87 \mathrm{~ms}$, and the stress in the region away from the center area decreases gradually. At the same time, there is also stress between the \#2 ball and \#3 ball, which indicates that the impact energy received by the \#2 ball is transferred rapidly to the \#3 ball, then the stress between the \#1 and \#2 balls decreases gradually, and the stress between the \#2 and \#3 ball increases gradually. At $1.0 \mathrm{~ms}$, as shown in Fig. 7(b), the maximum stress between the \#2 and \#3 balls is about $488 \mathrm{MPa}$, and the stress between the \#3 and \#4 balls appears. At $1.28 \mathrm{~ms}$, as shown in Fig. 7(c), the impact load of the drop ball is transmitted downwards. In turn, the stress in the \#1, \#2 and \#3 balls decreases, and the stress between the $\# 3$ and \#4 balls reaches a larger value. Because the \#4 ball is an immovably rigid body, the absorption and transmission of 
impact energy at the lower part of the \#3 ball results in elastoplastic deformation. At the same time, \#4 has a reaction force to \#3 grinding ball, and the reaction force transfers upward in turn. By $1.37 \mathrm{~ms}$, as shown in Fig. 7(d), the stress between the \#3 and \#4 balls decreases under the influence of the reaction force, and a greater instantaneous equivalent stress is produced again in the impact zone of the \#2 and \#3 balls. Under the influence of the reaction force, the \#1 and \#2 grinding balls continue to move upward, and at $3.5 \mathrm{~ms}$, the \#2 and \#3 balls are ejected and separated, as shown in Fig. 7(e). Figure 7 describes the motion state, energy transfer process, and instantaneous stress distribution of the ball in the process of dropping. It can be seen that the trajectory of the \#2 ball is complex, and the stress value is the highest in the whole impact process. Therefore, the \#2 ball, which is vulnerable to failure, is selected to study the distribution of the residual stress at $3.5 \mathrm{~ms}$ (Fig. 8). (a)

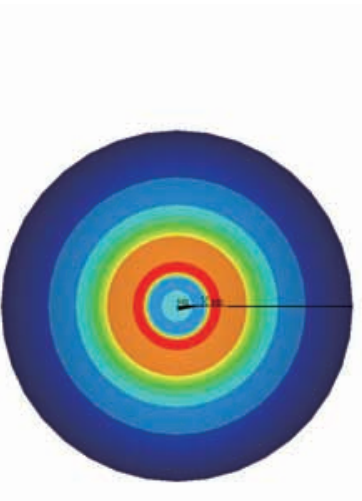

Stress $(\mathrm{Pa})$
$1.12 \times 10^{6}$
$4.82 \times 10^{7}$
$9.53 \times 10^{7}$
$1.42 \times 10^{8}$
$1.90 \times 10^{8}$
$2.37 \times 10^{8}$
$2.84 \times 10^{8}$
$3.31 \times 10^{8}$
$3.78 \times 10^{8}$
$4.25 \times 10^{8}$

(b)

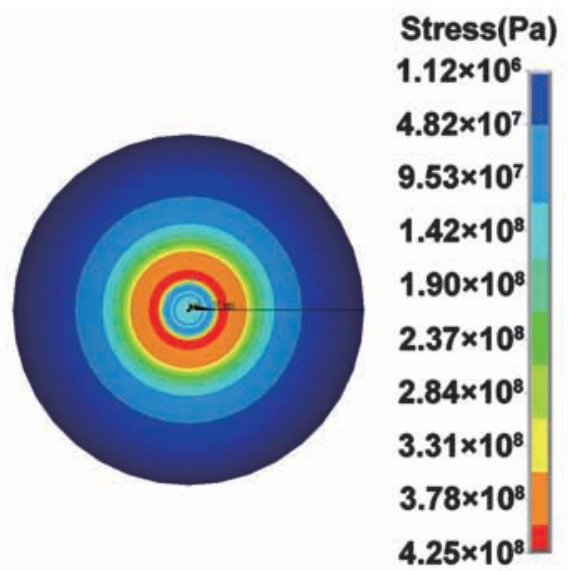

Fig. 8: Mises equivalent stress distribution of \#2 ball after single impact: (a) Upper stress ring; (b) Lower stress ring

In Fig. 8, the complete three-dimensional model of the \#2 ball is adopted, and Fig. 8(a) and Fig. 8(b) respectively show the equivalent stress distribution at the contact ends of the \#2 ball in Fig. 7(e). It can be seen that the residual stress on the upper and lower ends of the ball is relatively small, and the greater stress is distributed around the central area, and its distribution is annular. In Fig. 8(a), the larger stress ring (inner diameter of about $25 \mathrm{~mm}$ and outer diameter of about $50 \mathrm{~mm}$ ) appears. Compared with the upper end of the ball, the diameter of the higher stress ring at the lower end is smaller $(20 \mathrm{~mm}$ $45 \mathrm{~mm}$ ). It can be seen that the region of the stress ring is precarious and can easily fail under the impact process of the grinding ball.

In order to study the stress distribution of the $\# 2$ ball [Fig. 7(e)] in the impact direction (Y-direction) and the vertical impact direction (X-direction), the equivalent stress diagram of the \#2 ball is rotated by $90^{\circ}$, and it is recorded as Paths (1) and (3) in the Y-direction and Paths (2) and (4) in the X-direction, as shown in Fig. 9.

The distribution of residual stress in the $\mathrm{X}$ and $\mathrm{Y}$ directions of each point on the Paths (1) and (3) is shown in Fig. 10. In Fig. 10, it can be seen that the stress at both ends of the ball in the Y-direction is almost zero, and then the compressive stress gradually increases towards the center. The peak compressive stresses at the upper and lower ends appear at a depth of about 5-15 $\mathrm{mm}$ from the surface, and then the compressive stress gradually decreases. The stress is zero at a position of about $25 \mathrm{~mm}$ and $20 \mathrm{~mm}$ from both ends, and then the compressive stress is changed into tensile stress, which almost no longer changes after slightly rising. It can be seen that in the

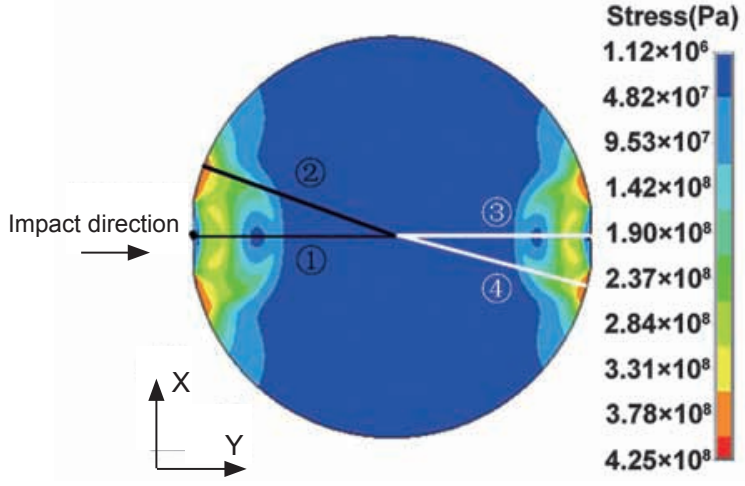

Fig. 9: Mises equivalent stress distribution of \#2 CADI grinding ball after single impact

Y-direction, the compressive stress at both ends of the grinding ball is greater and the tensile stress at the center is lower. The distribution and change of the stress in the X-direction are similar to those in the Y-direction, but there is a thin tensile stress layer on the surface of the ball, and then it is under compression at both ends with tension in the middle. The compressive stress in the $\mathrm{X}$-direction is greater than that in the Y-direction, and the tensile stresses in the $\mathrm{X}$ and $\mathrm{Y}$ directions are almost equal.

Only the stress distribution in the inner axis of the ball (as shown in Fig. 10, Paths (1) and (3) was analyzed above, and the distribution of the equivalent stress in the other directions (Paths (2) and (4) in Fig. 9) is shown in Fig. 11. Paths (2) and (4) are the distance from both ends of the ball to the center of the ball. The angles between the Paths (2) and (4) and the axial 


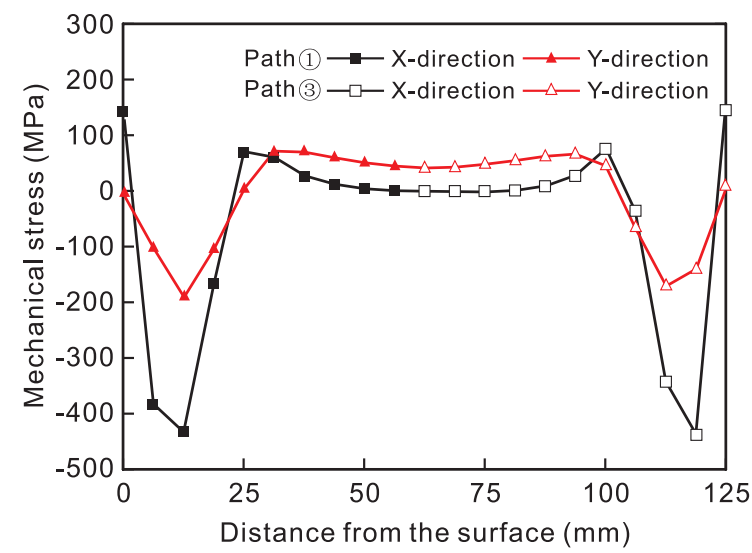

Fig. 10: Stress distribution on Paths (1) and (3) of \#2 ball after impact

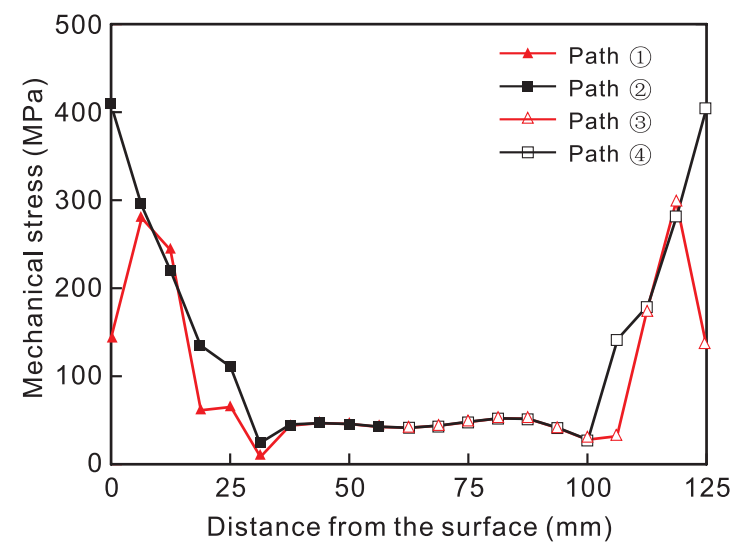

Fig. 11: Stress distribution on Paths (2) and (4) of \#2 ball after impact

direction (1) and (3) are $20^{\circ}$ and $15^{\circ}$, respectively, as shown in Fig. 9. As can be seen in Fig. 11, compared with the equivalent stresses in Paths (1) and (3), the maximum equivalent stress (about $400 \mathrm{MPa}$ ) in Paths (2) and (4) decreases from the surface to the center of the ball due to the gradual attenuation of impact energy in the transferring process. The minimum equivalent stress is about $30 \mathrm{MP}$ at about $25 \mathrm{~mm}$ from the surface of the ball, and then the equivalent stress gradually tends to be stable and the stress value is very low. It can be seen that the stress acting on the surface of the grinding ball is great, and the stress in the center is almost zero.

\subsection{Analysis of peeling layer of CADI grinding ball}

Figure 12 shows the peeling layers of 3.0wt.\% Mn CADI grinding ball. It can be seen that the diameters of the layers are $47 \mathrm{~mm}$ and $38 \mathrm{~mm}$, respectively, and the thickness of the layers is $4 \mathrm{~mm}$ and $6 \mathrm{~mm}$, thus CADI grinding ball failed according to the failure judgment standard of a grinding ball.

From the comprehensive analysis of the falling-ball's stress as shown in Figs. 8 and 9, it can be seen that the stress on the ball during impact is mainly distributed in the surface layer and subsurface layer, and the major stress is mainly distributed on the annular cross-section perpendicular to the impact direction, where the diameter of the annular cross-section is between 20$50 \mathrm{~mm}$. Comparing Figs. 8-9 with 12, it can be seen that the actual peeling layer size of the grinding ball is within the circle range of simulated large stress section. The stress simulation of the grinding ball in the process of dropping is in good agreement with the actual situation, which has certain guiding significance for the application of the grinding ball.

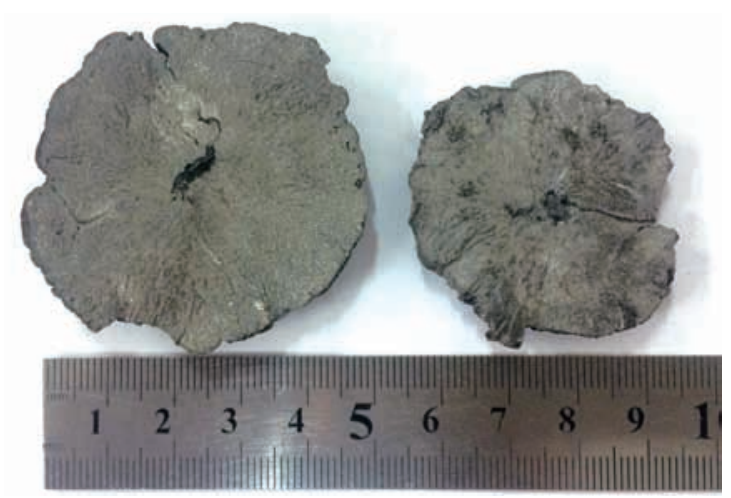

Fig. 12: Peeling layers of $\Phi 125 \mathrm{~mm}$ CADI grinding balls

Further observation on the morphology of the peeling layer is shown in Fig. 13(a). It can be seen that there are defects in the center of the peeling layer, and the crack fringe is centered on the defect and radiated around. EDS is carried out on the defect of the peeling layer, and the result is shown in Fig. 13(b). It can be seen that the defects are mainly oxide-based impurities, which can accelerate spalling of a CADI grinding ball.
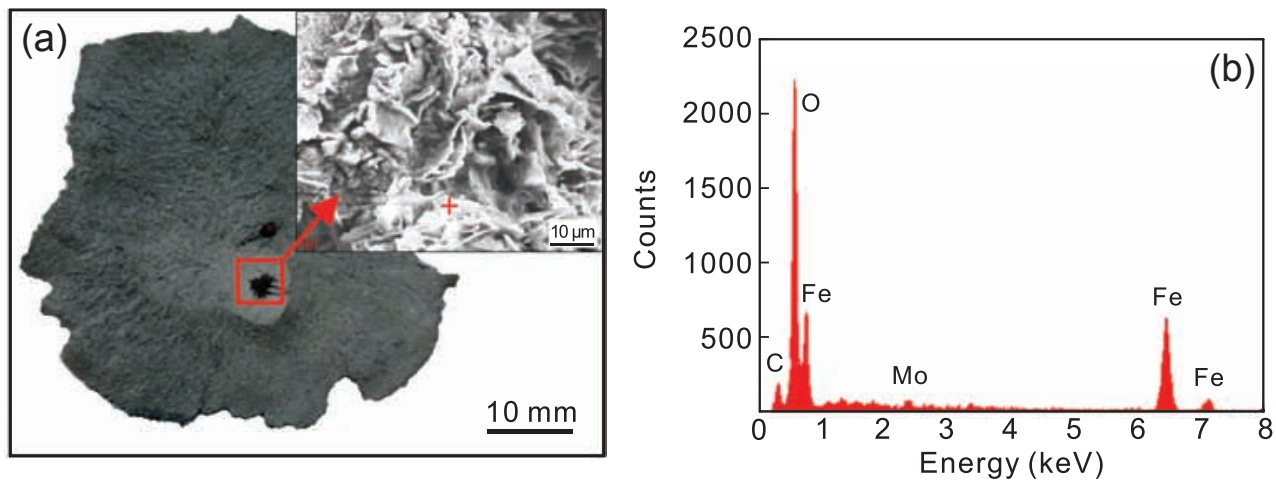

\begin{tabular}{ccc}
\hline Element & wt.\% & at. \% \\
\hline C & 11.40 & 22.22 \\
O & 39.19 & 57.34 \\
Mo & 1.57 & 0.38 \\
Fe & 47.84 & 20.05 \\
Matrix & Correction & ZAF \\
\hline
\end{tabular}

Fig. 13: EDS analysis of the peeling layer: (a) peeling layer; (b) EDS analysis results 


\section{Conclusions}

(1) With the increase of Mn content, the spalling amount of impact hardening layer of CADI grinding ball increases significantly. The spalling amount of the $2.6 \mathrm{wt} . \% \mathrm{Mn}$ CADI grinding ball is 3.4 times of the $2.0 \mathrm{wt} . \% \mathrm{Mn}$ grinding ball, and about 2 times of the $2.3 \mathrm{wt} . \% \mathrm{Mn}$ grinding ball. The spalling amount of the 3.0wt.\% Mn CADI grinding ball is the greatest, which is more than 5 times that of the $2.6 \mathrm{wt} . \% \mathrm{Mn}$ CADI grinding ball.

(2) The results of ANSYS/LS-DYNA simulation show that the maximum residual stress does not appear in the center of the contact area after a single impact, but in the squeeze zone around the contact area, forming a stress ring with a diameter of about $20-50 \mathrm{~mm}$.

(3) The actual size of the peeling layer of a CADI grinding ball is consistent with the numerical simulation, which indicates that the stress in the ball is one of the key failure factors.

(4) Oxide-based impurities in a CADI grinding ball accelerates the spalling of the grinding ball in service.

\section{Acknowledgements}

This work was financially supported by the Natural Science Foundation of Hebei Province of China under Grant Nos. E2016202100 and E2017202095, the National Natural Science Foundation of China (NSFC) under Grant No. 51601054, the Scientific and Technological Transformative Project of Tianjin Supporting Beijing-Tianjin-Hebei under Grant No. 18YFCZZC00030.

\section{References}

[1] Hebbar R. Investigation on grinding wear behaviour of austempered ductile iron as media material during comminution of iron ore in ball mills. Transactions of the Indian Institute of Metals, 2011, 64(3): 265-269.

[2] Sun X G, Wang Y, Li D Y, et al. Modification of carbidic austempered ductile iron with nano ceria for improved mechanical properties and abrasive wear resistance. Wear, 2013, 301: 116-121.

[3] Chiniforush E A, Yazdani S, Nadiran V. The influence of chil thickness and austempering temperature on dry sliding wear behaviour of a Cu-Ni carbidic austempered ductile iron (CADI). Kovove Materialy-Metallic Materials, 2018, 56(4): 213-221.

[4] Cheng $H$ Q, Fu H G, Lin J, et al. Effect of Cr content on microstructure and mechanical properties of carbidic austempered ductile iron. Materials Testing, 2018, 60(1): 31-39.

[5] Yang P H, Fu H G, Nan R, et al. Effect of Ti modification on microstructures and properties of carbidic austempered ductile iron. Journal of Materials Engineering and Performance, 2019, 28(4): 2335-2347.

[6] Nan R, Fu H G, Ma S Q, et al. Microstructure and properties of Cu-bearing carbidic austempered ductile iron. International Journal of Materials Research, 2019, 110(7): 621-635.

[7] Yang P H, Fu H G, Lin J, et al. Thermodynamic and kinetic analysis of austenite homogenization on carbidic ductile iron. Steel Research International, 2019, https://onlinelibrary.wiley. com/doi/full/10.1002/srin.21900256.
[8] Laino S, Sikora J A, Dommarco R C. Development of wear resistant carbidic austempered ductile iron (CADI). Wear, 2008, 265(1-2): 1-7.

[9] Laino S, Sikora J, Dommarco R C. Wear behavior of CADI operating under different tribosystems. ISIJ International, 2010, 50(3): 418-424.

[10] Ivan P D, Laino S, Cesar D R. Study of the carbidic ADI performance under RCF condition. Materia-Rio de Janeiro, 2018, 23(2).

[11] Pedro D I, Dommarco R C. Rolling contact fatigue resistance of carbidic austempered ductile iron (CADI). Wear, 2019, 418419: 94-101.

[12] Dakre V, Peshwe D R, Pathak S U, et al. Effect of austenitization temperature on microstructure and mechanical properties of low-carbon-equivalent carbidic austempered ductile iron International Journal of Minerals Metallurgy and Materials, 2018, 25(7): 770-778.

[13] Cheng $H$ Q, Fu H G, Ma S Q, et al. Effects of austenitizing process on microstructures and properties of carbidic austempered ductile iron. Materials Research Express. 2018, 6(1).

[14] Nan R, Fu H G, Yang P H, et al. Effect of austenitizing temperature on the microstructure evolution and properties of Cu-bearing CADI. Materials Testing, 2019, 61(9): 865-874.

[15] Yang P H, Fu H G, Zhao X W, et al. Wear behavior of CADI obtained at different austenitizing temperatures. Tribology International, 2019, 140: 105876.

[16] Liu J H, Wang K J, Li G L, et al. Development and Trends of CADI in domestic and abroad. Modern Cast Iron, 2015, (6) 40-45. (In Chinese)

[17] Peng Y C, Jin H J, Liu J H, et al. Effect of boron on the microstructure and mechanical properties of carbidic austempered ductile iron. Materials Science and Engineering $\mathrm{A}$ 2011, 529: 321-325

[18] Liu J H, Xiong P, Fu B G, et al. Effects of austempering temperature on microstructure and surface residual stress of carbidic austempered ductile iron (CADI) grinding balls. China Foundry, 2018, 15(3): 173-181.

[19] Zhang J H. The operating mode and forces analysis of mill ball in the mill. Journal of Huainan Mining Institute, 1998, 2(18): 48-52. (In Chinese)

[20] Kavicka F, Stransky K, Dobrovska J, et al. Numerical and experimental investigation of the temperature field of a solidifying massive ductile-cast-iron roller. Materiali in Tehnologije, 2012, 46 (4): 321-324.

[21] Kavicka F, Dobrovska J, Stransky K, et al. Temperature field and solidification structure of a ductile-cast-iron roller. Key Engineering Materials, 2014, 592-593: 197.

[22] Ma Z J, Tao D, Yang Z, et al. The effect of vermicularity on the thermal conductivity of vermicular graphite cast iron. Materials \& Design, 2016, 93: 418-422

[23] Stupak E. Investigation of fracture of inhomogeneous cast iron specimens. Mechanika, 2010, (1): 20-24.

[24] Ibrahim K M, El-Sarnagawy B, Saleh II, et al. Fatigue behaviour of notched ADI castings. International Journal of Cast Metals Research, 2014, 27(4): 250-256.

[25] Zhao X B, Peng Y C, Yang Z Y, et al. Numerical simulation of stress of CADI grinding ball and its failure analysis in falling ball test. Foundry, 2011, 60(6): 559-564. (In Chinese)

[26] Yu H Q, Chen J D. Principle of metal plastic forming. China Mechine Press, Beijing, 1999: 207. (In Chinese) 